\title{
A Combined Surgical-Orthodontic Treatment of Two Infundibularis Mesiodentes - A Case Report
}

\author{
Vassil I. Peev ${ }^{1 *}$, Iliya V. Peev ${ }^{2}$, Mary Hristamyan-Cilev ${ }^{3}$ \\ ${ }^{1}$ Dental Clinic, Plovdiv, Bulgaria \\ ${ }^{2}$ EO Dent Dental Clinic, Sofia, Bulgaria \\ ${ }^{3}$ Department of Epidemiology and Disaster Medicine, Faculty of Public Health, Medical University of Plovdiv, \\ Bulgaria
}

*Corresponding Author: Vassil I. Peev, Faculty of Public Health, Department of Social Medicine and Public Health, Medical University, Plovdiv, Bulgaria, Tel: +359887426462; E-mail: drvaskopeev@abv.bg

Received: 23 May 2018; Accepted: 11 June 2018; Published: 13 June 2018

\begin{abstract}
Aim: Aim of the article is to present a clinical protocol for surgical management of a case with two mesiodentes. The detained and inferior position of 21 is the other problem which should be considered during the orthodontic treatment.
\end{abstract}

Tasks: The tasks are to remove them from the arch and to involve the first left incisor 21 in the appropriate place. The main reason for surgical manipulations is the lack of esthetics.

Materials and methods: The patient is 23 year-old female with Diabetes Mellitus Type II. The malocclusion is classified as Angle Class I in the addition with two supernumerary teeth - both on maxillary jaw. The one is impacted, with canine form and the other mesiodens take place of the first central incisor with tuberculate form.

Results: During the surgical treatment, factors such as the general condition of the patient should be considered and a cost-benefit analysis should be performed. Problems with orthodontic treatment are related to the weighing and resorption process of 21 or adjacent teeth. The high motivation of the patient is important for optimal treatment and presents cooperation in the best light.

Keywords: Mesiodens; Tooth extrusion; Combined orthodontic-surgical treatment 


\section{Introduction}

Etiological factors that are relevant to the formation of mesiodens not yet been fully explored. It is assumed that the relationship has the proliferation of the dental lamina, as well as some genetic factors. The incidence rate reported from some authors is between $0.15 \%$ to $1.9 \%$ of the population [1, 2, 3]. This implies competence and adequate decision-making by the general practitioner [4]. Mesiodens can lead delayed or ectopic eruption of permanent teeth (usually incisors) as well as changes in occlusion and aesthetics of the patient [5]. It is therefore important for the clinician to diagnose a mesiodens early in development to allow for optimal yet minimal treatment. For decisionmaking of combined surgical-orthodontic treatment, socio-demographic factors, such as education and culture, are from importance [6]. Here is the role of the dentist for early detection of the problem and restoration of the function even before the growth of the maxillo-facial jaws [7]. Treatment options may include surgical extraction of the mesiodens [8].

\section{Some of the Problems Associated with Supernumerary Teeth}

- $\quad$ Failure of Eruption;

- Displacement;

- Crowding;

- Pathology;

- Aesthetics;

- Social rehabilitation [10].

\section{Aim}

The aim of the study is to present a clinical protocol for the treatment of a case with two infundibularis mesiodentes.

\section{Case History}

The patient was 23-year-old girl with an Angle Class I malocclusion. The data from X-ray examination show a permanent dentition and two mesiodentes, infundibularis type with canine and premolar form - both on maxillary jaw. In addition to the clinical approach and a family history, it is necessary to specify the paraclinical studies related to the general condition and the oral status of the patient (Figure 1). Supernumeraries and inferior position are visible at Figure 2. The evaluation of tooth-jaw relationships and analysis of a panoramic X-ray image are necessary for the optimal surgical treatment.The patient has not been diagnosed to date by another dentist.

\subsection{Clinical diagnosis and management of supernumerary (mesiodens)}

In the present case the management and the clinical protocol of the treatment depends on the type and position of both mesiodentes -one of them with impacted position [9, 10]. The extraction of the oral mesiodens is indicated because of esthetic and other considerations, such as eruption delay of 21 [11, 12]. The oral image and the specific form of the mesiodens are present at Figure 3. The left central incisor is held and it's inferior position shows a crown height lack from horizontal line. The shape of the oral mesiodens is tuberculate and is larger than the typical conical 
form. This suggests that compression and lagging in front of the upper jaw will not be so great. The form of the mesiodens appears to be an advantage for the patient, as it almost retains the place for 21 and remains as Angle Class I malocclusion, not Class III, for ex.

\section{Results}

One month after the extraction of the oral mesiodens and insertion of brackets guidelines are given to the patient for night wearing of elastics (Figure 4).

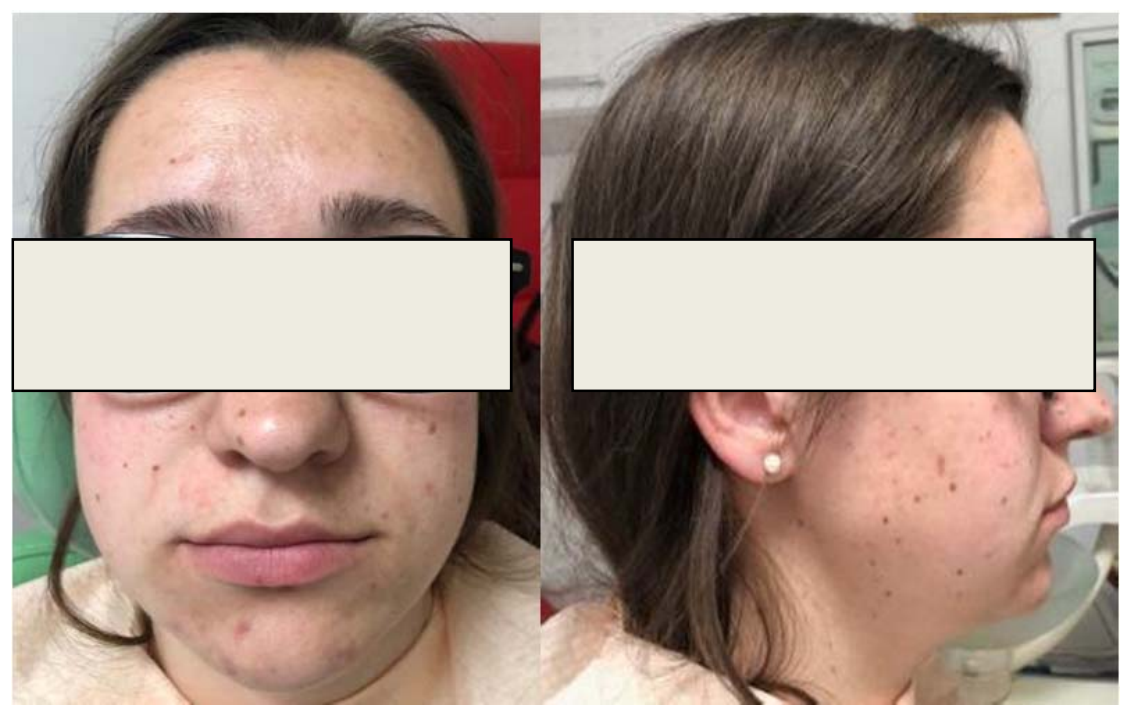

Figure 1: Facial image of the patient (23 y.old female) before the treatment. A. Frontal view at rest. B. The right profile at rest with lips relaxed.

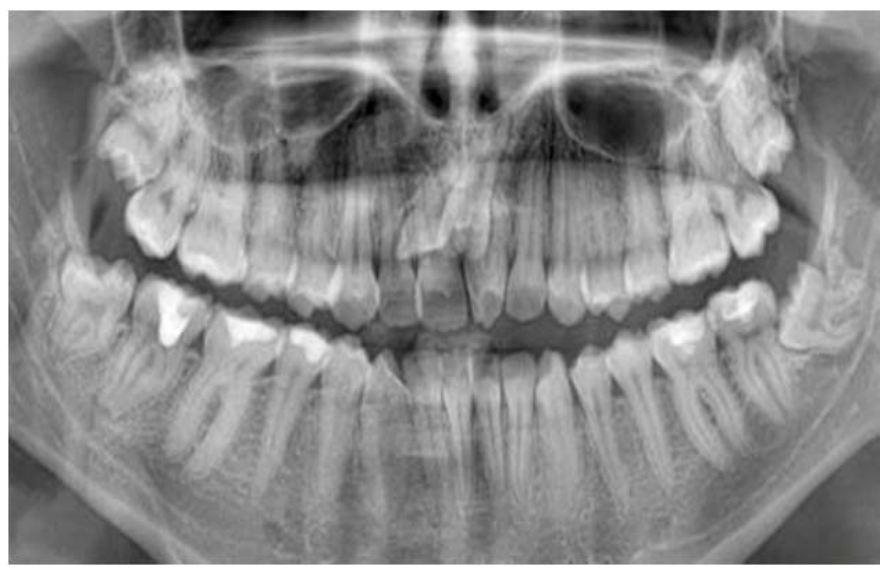

Figure 2: Supernumeraries and eruption disturbances at Panoramic radiographs. 


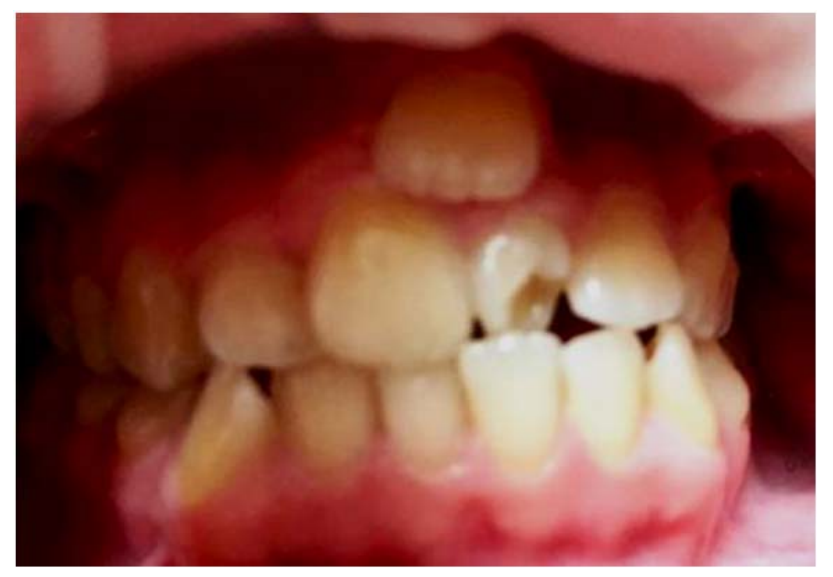

Figure 3: The oral image and the position of 21 and visible tuberculate mesiodens.

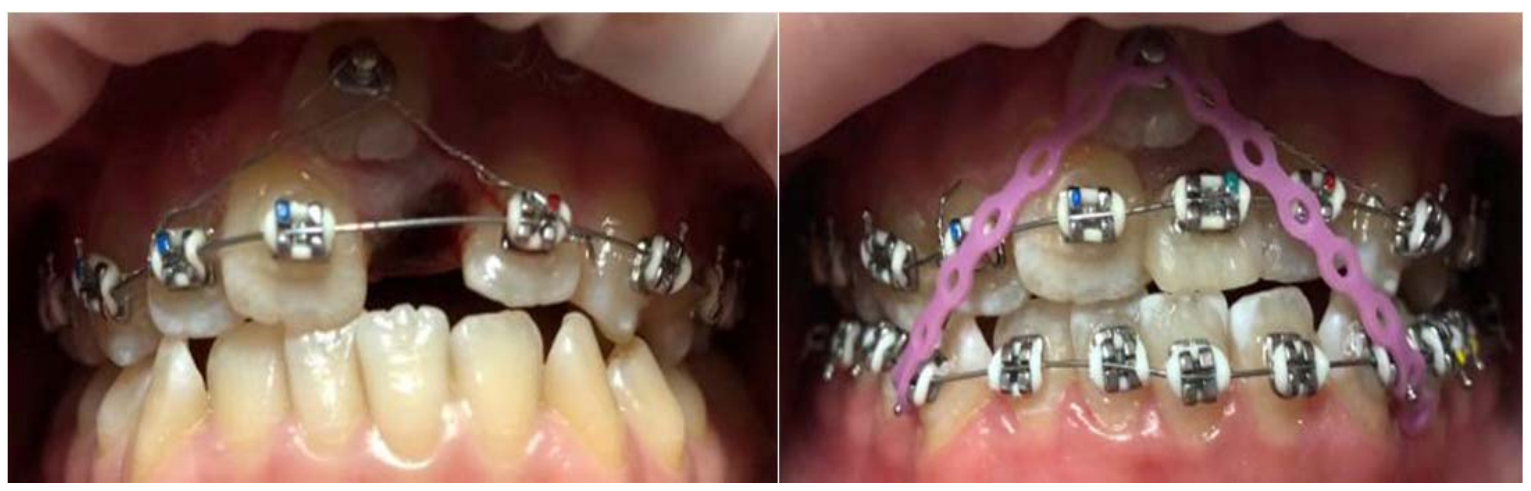

Figure 4: A. Initial surgical treatment B; An orthodontic approach of a rare case with two infundibularis mesiodentes. Replacement of a false 21 tooth because of aesthetic considerations and initial alignment of 21. Elastics for the night wearing.

\section{Conclusions}

It turns out that despite the differences in the shape of the other teeth, the mesiodens is not as recognizable by dental practitioners. This is one of the reasons for the delay in a decision on the treatment, which has predominantly social consequences for the patient. Extraction of mesiodentes and the following surgical-orthodontic treatment can improve the facial aesthetics and will prevent the patient's social isolation especially to this young lady.

\section{References}

1. Liu JF. Characteristics of premaxillary supernumerary teeth: a survey of 112 cases. ASDC J Dent Child 62 (1995): 262-265.

2. Levine N. The clinical management of supernumerary teeth. J Can Dent Assoc 28 (1961): 297-303. 
3. Brook AH. Dental anomalies of number, form and size: their prevalence in British schoolchildren. J Int Assoc Dent Child 5 (1974): 37-53.

4. Peeva Yu. Personal recommendations and tips to orthodontic patients: A Systematic Review. J Oral Med, iMedPub Journals ISSN 0022-3247, 1 (2017).

5. Van Buggenhout G, Bailleul-Forestier I. Mesiodens. Eur J Med Genet 51 (2008): 178-181.

6. Peeva Yu. The influence of certain socio-demographic and economic factors for the need of orthodontic treatment. OALib J 11 (2017): e4112.

7. Peeva Yu. The gap of awareness in orthodontic treatment. OALib J 4 (2017): 74089.

8. Bartolo A, Camilleri A, Camilleri S. Unerupted incisors-characteristic features and associated anomalies. Eur J Orthod 32 (2010): 297-301.

9. Solares R. The complications of late diagnosis of anterior supernumerary teeth: case report. ASDC J Dent Child 57 (1990): 209-211.

10. Peeva Yu, Yankovski Hr, Peev I. Discrepancies in orthodontic awareness among parents and their children from Plovdiv, Bulgaria. American Journal of Public Health Research 4 (2016): 23-27.

11. Yagüe-García J, Berini-Aytés L, Gay-Escoda C. Multiple supernumerary teeth not associated with complex syndromes: a retrospective study. Med Oral Patol Oral Cir Bucal 14 (2009): E331-E336.

12. Peeva Yu. Epidemiology of dental malocclusions of 11-14-years-old schoolchildren, compared meanings of sociological and descriptive methods. Public health and health care in Greece and Bulgaria: The Challenge of the cross-border collaboration (Greece), 2010, Plovdiv, Bulgaria. Papazissis publishers, Athens, ISBN: 978-960-02-2630-0 (2011): 283-291.

Citation: Vassil I. Peev, Iliya V. Peev, Mary Hristamyan-Cilev. A Combined Surgical-Orthodontic Treatment of Two Infundibularis Mesiodentes - A Case Report. Dental Research and Oral Health 1 (2018): 017-021.

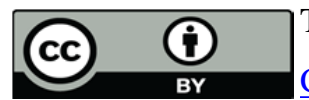

This article is an open access article distributed under the terms and conditions of the Creative Commons Attribution (CC-BY) license 4.0 